\title{
Identification of Genes Regulating Gene Targeting by a High-Throughput Screening Approach
}

\author{
Fabien Delacôte, ${ }^{1}$ Christophe Perez, ${ }^{1}$ Valérie Guyot, ${ }^{1}$ Catherine Mikonio, ${ }^{2}$ Pierrick Potrel, ${ }^{2}$ \\ Jean-Pierre Cabaniols, ${ }^{2}$ Christophe Delenda, ${ }^{2}$ Frédéric Pâques, ${ }^{1}$ and Philippe Duchateau ${ }^{1}$ \\ ${ }^{1}$ Cellectis SA, 102 Avenue Gaston Roussel, 93340 Romainville Cedex, France \\ ${ }^{2}$ Cellectis Bioresearch, 102 Avenue Gaston Roussel, 93340 Romainville Cedex, France
}

Correspondence should be addressed to Frédéric Pâques, frederic.paques@cellectis.com

Received 25 November 2010; Accepted 23 January 2011

Academic Editor: Emery H. Bresnick

Copyright ( $) 2011$ Fabien Delacôte et al. This is an open access article distributed under the Creative Commons Attribution License, which permits unrestricted use, distribution, and reproduction in any medium, provided the original work is properly cited.

\begin{abstract}
Homologous gene targeting (HGT) is a precise but inefficient process for genome engineering. Several methods for increasing its efficiency have been developed, including the use of rare cutting endonucleases. However, there is still room for improvement, as even nuclease-induced HGT may vary in efficiency as a function of the nuclease, target site, and cell type considered. We have developed a high-throughput screening assay for the identification of factors stimulating meganuclease-induced HGT. We used this assay to explore a collection of siRNAs targeting 19,121 human genes. At the end of secondary screening, we had identified 64 genes for which knockdown affected nuclease-induced HGT. Two of the strongest candidates were characterized further. We showed that siRNAs directed against the ATF7IP gene, encoding a protein involved in chromatin remodeling, stimulated HGT by a factor of three to eight, at various loci and in different cell types. This method thus led to the identification of a number of genes, the manipulation of which might increase rates of targeted recombination.
\end{abstract}

\section{Introduction}

The transfection of cells with exogenous DNA can be used to generate stable transformants with the exogenous sequence integrated into their genomes by random insertion (RI) or targeted integration driven by homologous recombination. In the case of homologous recombination, the integration of DNA into the genome is referred to as "homologous gene targeting" (HGT). Both RI and HGT depend on DNA double-strand break (DSB) repair mechanisms.

DSBs are particularly hazardous events in cells. Two different and competing mechanisms repair DSBs. Homologous recombination (HR) involves the use of homologous sequences as a template for restoring genomic integrity upon DSB induction and is considered to be an error-free mechanism. Genetic and biochemical studies have shown that $\mathrm{HR}$ in yeast is mediated by the RAD52 epistasis group of genes [1], which are required to various extents for HGT. For example, almost no HGT is observed in the absence of a functional RAD52 gene, but substantial levels of recombination are observed in absence of RAD51 and RAD57 [2]. Homologs of these genes have been identified in vertebrates, including RAD51, RAD51B, RAD51C, RAD52, $R A D 54, X R C C 2$, and $X R C C 3$, which have been shown to be necessary for HGT in the DT40 chicken lymphoid cell line [3-7]. In mouse embryonic stem (ES) cells, HGT is decreased slightly by mutations in BRCA2 [8], strongly by mutations in BRCA1 [9] and RAD54 [10] and is completely abolished by mutations in ERCC1/XPF [11]. By contrast, nonhomologous end joining (NHEJ) requires little or no homology for DSB repair and is often associated with insertions and/or deletions at the DSB site [12]. This mechanism is therefore considered to be error prone. Several factors involved in NHEJ have been identified, including the Ku DNA-binding heterodimers, the DNA-PKcs protein kinase, Artemis, DNA ligase IV (Lig4), and associated partners XRCC4 and XLF/Cernunnos [12]. These proteins differ in their impact on the efficiency of the NHEJ process, but the absence of XRCC4, Lig4, and $\mathrm{Ku}$ strongly increases the proportion of error-associated DSB repair events [13-16]. Early studies reported that Chinese 
hamster cell lines with mutations in XRCC4 (xrs-1) or Ku80 (xrs-6) had lower random integration frequencies than the wild type (WT) $[17,18]$. Furthermore, mouse cells with a mutant DNA ligase IV were found to have significantly lower random integration frequencies than WT cells [19]. Finally, $\mathrm{Ku} 80$ and DNA ligase IV deficiencies in plants lead to defective T-DNA integration [20]. All these findings are consistent with a role for NHEJ in random integration events. However, the precise mechanism of random integration remains to be determined.

HGT provides the ultimate genetic tool for investigating gene function, as it can be used for the specific modification of almost any genomic sequence. Moreover, HGT may provide an alternative approach for gene therapy strategies, because targeted integration into a genomic safe harbor may reduce the risks of insertional mutagenesis. However, the low frequency of homologous gene targeting has been a major obstacle to the use of this technology. Indeed, random integration appears to be the major DNA integration pathway in most organisms, including mammals and higher plants (for review, see [21]), with the exception of S. cerevisiae and a handful of other species and cell types. Several reports have also indicated that HR is efficient essentially during the late $S$ and G2 phases of the cell cycle [22-29], suggesting that it may be difficult to make use of HGT in postmitotic cells.

Various approaches have been tested for improving gene targeting performances. Selection procedures have been used, to eliminate unwanted random integration $[30,31]$. However, although these methods increase the yield of targeted events in transformants, they have no impact on absolute gene targeting frequencies- the number of targeted events per transfected cell. Many other studies have aimed to increase the efficiency of HR. One of the most successful methods in current practice is based on the use of rare cutting endonucleases, such as meganucleases or zinc finger nucleases (ZFNs) to induce a DSB in the targeted gene [21]. Meganucleases are natural endonucleases that induce targeted recombination in living cells $[32,33]$, whereas ZFNs are generated by fusing a zinc finger-based DNAbinding protein with the catalytic domain of the bacterial FokI endonuclease [34-36]. Robust stimulation of HGT by a factor of 100 , or even 1000 , has been achieved by several groups in this way, resulting in several percents of targeted events in immortalized cells [37-41]. However, the degree of stimulation achieved is highly variable and depends on the nuclease [37] and other factors. For example, a zinc finger protein recognizing a sequence present in the plant SurA and SurB genes has been shown to induce different levels of targeted mutagenesis in these two genes [38], suggesting that target accessibility or the efficacy of a DNA repair pathway may be locus-dependent. The efficiency of the process also depends on cell type: by using nonintegrative lentiviral vectors rather than transfection, Lombardo et al. induced up to $50 \%$ HGT events at the CCR5 locus in K562 and Jurkat cells, about $5 \%$ in ES cells, and almost $0.1 \%$ in CD34+ cord blood progenitor cells [37]. Similarly, Zou et al. achieved much lower levels of DSB-induced recombination at the PIG$A$ locus in human ES cells and induced pluripotent stem cells (iPS) $\left(2-4 \times 10^{-4}\right.$ and $\times 10^{-5}$, resp.) than in 293 cells
(3\%) [40]. These differences may be due to lower efficiencies of vectorization and/or nuclease expression, differences in the likelihood of homologous recombination in different cell types, or a combination of these factors. Nevertheless, there is still room for improvement. Given the cell cycle dependence of homologous recombination, Urnov et al. and others have induced simple reversible cell cycle arrest in the G2 phase with reagents such as vinblastine, resulting in a small but significant increase in nuclease-induced HGT in immortalized cell lines $[38,39]$.

Another approach involves direct modulation of the cellular DNA repair machinery. Several groups have adopted this strategy and have tried to stimulate HGT by overproducing DNA repair proteins [42-46]. Overexpression of the human RAD51 gene resulted in a two to three times increase in HGT [43], but higher rates (10 to 64 times higher) have been reported in other studies involving overproduction of the bacterial RecA [44] or yeast Rad52 [46] proteins in mammalian cells or of yeast Rad54 in Arabidopsis [45]. Other groups have investigated the impact of NHEJ inhibition on HGT, with conflicting results in some cases. Pierce et al. observed that HGT frequencies were similar in wt, $\mathrm{Ku}^{-1 /}$, $D N A-\mathrm{PK}^{-/-}$, and $\mathrm{Xrcc}^{-/-}$mouse ES cells [47]. Similarly, Domínguez-Bendala observed a similar absence of HGT stimulation in Ku80- and DNA-PK-deficient cells, although they did observe a significant increase in HGT following the knockdown of PARP-1, an unrelated gene [48]. By contrast, downregulation of the Ku70 and XRCC4 genes by siRNAs in human cells leads to significant 30 times increase in the HGT/RI ratio at the HPRT locus [49].

By combining the use of a nuclease to create a DSB in the targeted gene and the modulation of specific genes, it should be possible to achieve the synergistic stimulation of HGT. Various studies have shown that the efficiency of homologous recombination induced by a nuclease could further be enhanced by the overproduction or inactivation of DNA repair proteins $[47,50,51]$, although all these studies involved the $a$ priori identification of potential candidates on the basis of their role in DNA repair. Several genomewide RNAi screening analyses have recently improved our understanding of the DNA repair pathway [52-54]. Słabicki et al. identified 61 genes affecting DNA DSB repair in human HeLa cells [54]. The downregulation of 17 of these genes led to an increase in endonuclease-induced homologous recombination. However, this study assessed intrachromosomal recombination rather than gene targeting per se (recombination between an exogenous DNA sequence and a target chromosomal locus). It therefore seems likely that many other genes may be involved in the DSB-induced HGT mechanism.

We have developed a high-throughput screening system for a genome-wide study of factors affecting nucleaseinduced HGT. Using an assay monitoring the HGT induced by the I-SceI meganuclease, we screened a library of siRNAs and identified several genes for which downregulation was associated with a significant increase in HGT efficiency. Sixty-four candidates were confirmed by secondary screening. Two of these candidates, EP300 and ATF7IP, which are not known to be directly involved in DNA repair, were 
characterized further. We show here that the downregulation of these genes leads to a significant increase in the frequency of HGT at endogenous loci in human cells.

\section{Materials and Methods}

2.1. Cell Culture. The GM00847, cGPS HEK-293, and $293 \mathrm{H}$ cell lines were cultured in Dulbecco's modified Eagle's medium (dMEM) plus Glutamax supplemented with 10\% fetal calf serum, $2 \mathrm{mM}$ L-glutamine, $100 \mathrm{IU} / \mathrm{ml}$ penicillin, $100 \mu \mathrm{g} / \mathrm{ml}$ streptomycin, and $0.25 \mu \mathrm{g} / \mathrm{ml}$ amphotericin B (Fungizone) at $37^{\circ}$, under an atmosphere containing 5\% $\mathrm{CO}_{2}$. cGPS HEK-293 cells were grown in the presence of $0.1 \mathrm{mg} / \mathrm{ml}$ hygromycin B (Sigma). The E2 clone for the measurement of I-SceI-induced gene targeting with the luciferase reporter system was selected and maintained on

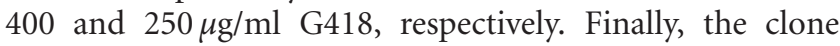
used for measuring I-SceI-induced gene targeting with the GFP reporter system was selected on $400 \mu \mathrm{g} / \mathrm{ml} \mathrm{G418}$ and $0.4 \mu \mathrm{g} / \mathrm{ml}$ puromycin. For cellular expansion, this clone was maintained in medium containing $200 \mu \mathrm{g} / \mathrm{ml} \mathrm{G418}$ and $0.2 \mu \mathrm{g} / \mathrm{ml}$ puromycin.

\subsection{Generation of Cell Lines for Primary and Secondary} Screening. For primary screening, we generated a cell line derived from GM00847 (Coriell Institute) carrying a luciferase-based reporter gene, as described in Figure 1(a). We electroporated $10^{6}$ GM00847 cells with $500 \mathrm{ng}$ of the gene-targeting substrate plasmid (Figure 1), linearized by $P v u \mathrm{I}$ digestion. Electroporation was carried out with the Amaxa kit, according to the manufacturer's instructions. Two days after transfection, $400 \mu \mathrm{g} / \mathrm{ml} \mathrm{G} 418$ were added to the cells. The selected clones were then amplified for genomic DNA extraction, for Southern blots to determine whether the transgene was present as a single copy.

For secondary screening, we generated a cell line derived from cGPSHEK293 (Cellectis Bioresearch, Romainville, France) carrying a GFP-based reporter gene, as described in Figure 3(a). We used $10^{6}$ cells to seed $10 \mathrm{~cm}$ tissue culture dishes on the day before transfection. We cotransfected cells with $3 \mu \mathrm{g}$ of gene targeting substrate and $2 \mu \mathrm{g}$ of I-CreI expression plasmid using Lipofectamine 2000 reagent (Invitrogen), according to the manufacturer's instructions. Twenty-four hours after transfection, the culture medium was replaced with fresh medium supplemented with $0.4 \mathrm{mg} / \mathrm{ml} \mathrm{G418}$. After 12 days of selection, the second selective agent, puromycin, was added at a concentration of $0.4 \mu \mathrm{g} / \mathrm{ml}$. After incubation for seven to nine days in the presence of both selective agents, single-colony clones were picked in 96-well plates. Double-resistant clones were analyzed by Southern blotting for integration at the I-CreI locus (data not shown).

2.3. Screening Assays. For primary screening, 14,000 cells per well were seeded in white 96-well plates on the day before transfection. Cells were transfected with $200 \mathrm{ng}$ of Luciferase Repair Matrix and I-SceI induction plasmid (RMLuc+I-SceI see Figure 1(b)) per well or with Luciferase Repair Matrix alone (RMLuc, see Figure $1(\mathrm{~b})$ ), with or without $33 \mathrm{nM}$ siRNA, in the presence of $0.8 \mu \mathrm{l}$ of Polyfect transfection reagent (Qiagen). We added $50 \mu \mathrm{l}$ of ONEGlo (Promega) to each well, 72 hours after transfection, and incubated the cells in the dark for 3 minutes before luciferase activity analysis (1 second/well) with a PHERAStar luminometer (BMG Labtech). For secondary screening, 15,000 and $10^{6}$ cells were seeded in 96-well plates or $10 \mathrm{~cm}$ dishes, respectively, on the day before transfection. Cells were transfected with $200 \mathrm{ng}$ (for 96-well plates) or $5 \mu \mathrm{g}$ (for $10 \mathrm{~cm}$ dishes) of RMGFP+ISceI (Figure 3) with or without siRNA at a final concentration of $33 \mathrm{nM}$, using $1.35 \mu \mathrm{l}$ and $90 \mu \mathrm{l}$ of Polyfect transfection reagent, respectively. Cells were trypsinized 96 hours after transfection, and the percentage of GFPpositive cells was monitored by flow cytometry (Guava Instruments). We monitored siRNA transfection efficiency with rhodamine-labeled siRNA coupled with flow cytometry detection. Transfection efficiency reached $73 \%$, indicating that the transfection conditions used were very good (data not shown). The ratio of the percentage of GFP+ cells for a specific siRNA over that for the siRNA control All Star (AS Qiagen) was used to determine the stimulation factor for each specific siRNA. The potential effect of siRNAs was assessed by applying Student's $t$-tests to the stimulation factor. Two controls siRNAs were used to validate siRNA transfection: the RAD51 and GFP siRNAs. The RAD51 and GFP siRNAs decreased the percentage of EGFP-positive cells by factors of six and four with respect to the control All Star (AS) siRNA, demonstrating that the siRNAs were active (Figure 4). All experiments carried out in 96-well plates (cell seeding, cell transfection, incubation, and luciferase detection) were performed with a Velocity 11 robot (Velocity, Palo Alto, CA). $Z$-scores were calculated with the following equation, $Z=(x-\mu) \sigma^{-1}$, where $x$ is the mean luciferase signal for a given siRNA, $\mu$ is the mean luciferase signal for the run, and $\sigma$ is the standard deviation of the run. Means and standard deviations were calculated excluding controls.

2.4. Targeted Integration at the hRAG1 Locus. On the day before transfection, $10^{6} 293 \mathrm{H}$ cells were seeded in $10 \mathrm{~cm}$ dishes. Cotransfection was performed with $3 \mu \mathrm{g}$ of meganuclease expression plasmid, $2 \mu \mathrm{g}$ of Knock-In matrix, and $33 \mathrm{nM}$ siRNA, in the presence of $90 \mu \mathrm{l}$ of Polyfect. The Knock-In plasmid has all the necessary characteristics favoring highly efficient homologous recombination at the endogenous hRAG1 locus in $293 \mathrm{H}$ cells. The left and right arms correspond to isogenic sequences of $2 \mathrm{~kb}$ and $1.2 \mathrm{~kb}$ in size, respectively, surrounding the RAG1 meganuclease recognition site. These two homologous arms are separated by a heterologous $1.7 \mathrm{~kb}$ fragment [55].

Twenty-four hours after transfection, cells were trypsinized and seeded in 96-well plates at a density of 10 cells per well. Two weeks after transfection, genomic DNA was extracted with the ZR96 Quick-gDNA kit (Zymo Research), according to the manufacturer's protocol. We screened for knock-in events by PCR, as described by Grizot et al. [55], 


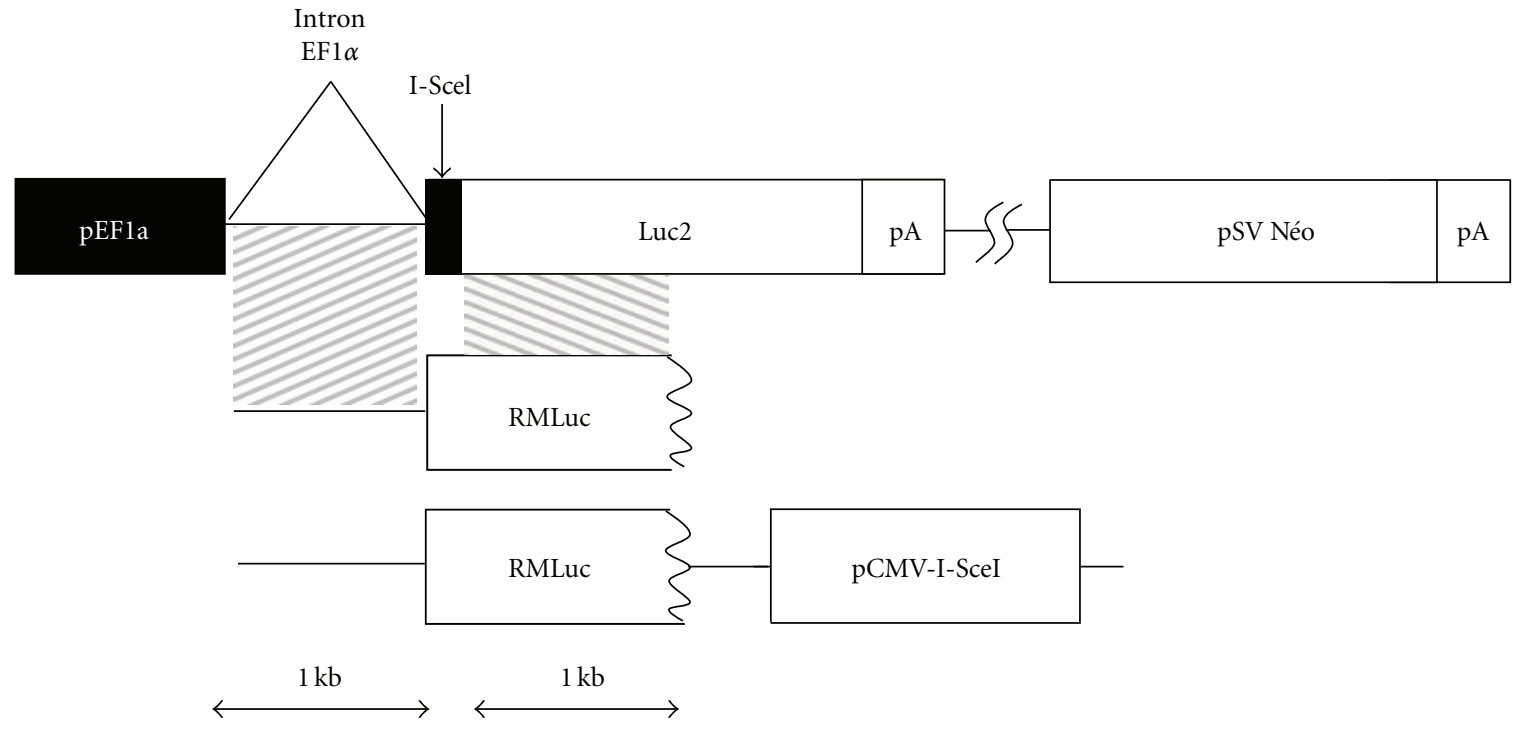

(a)
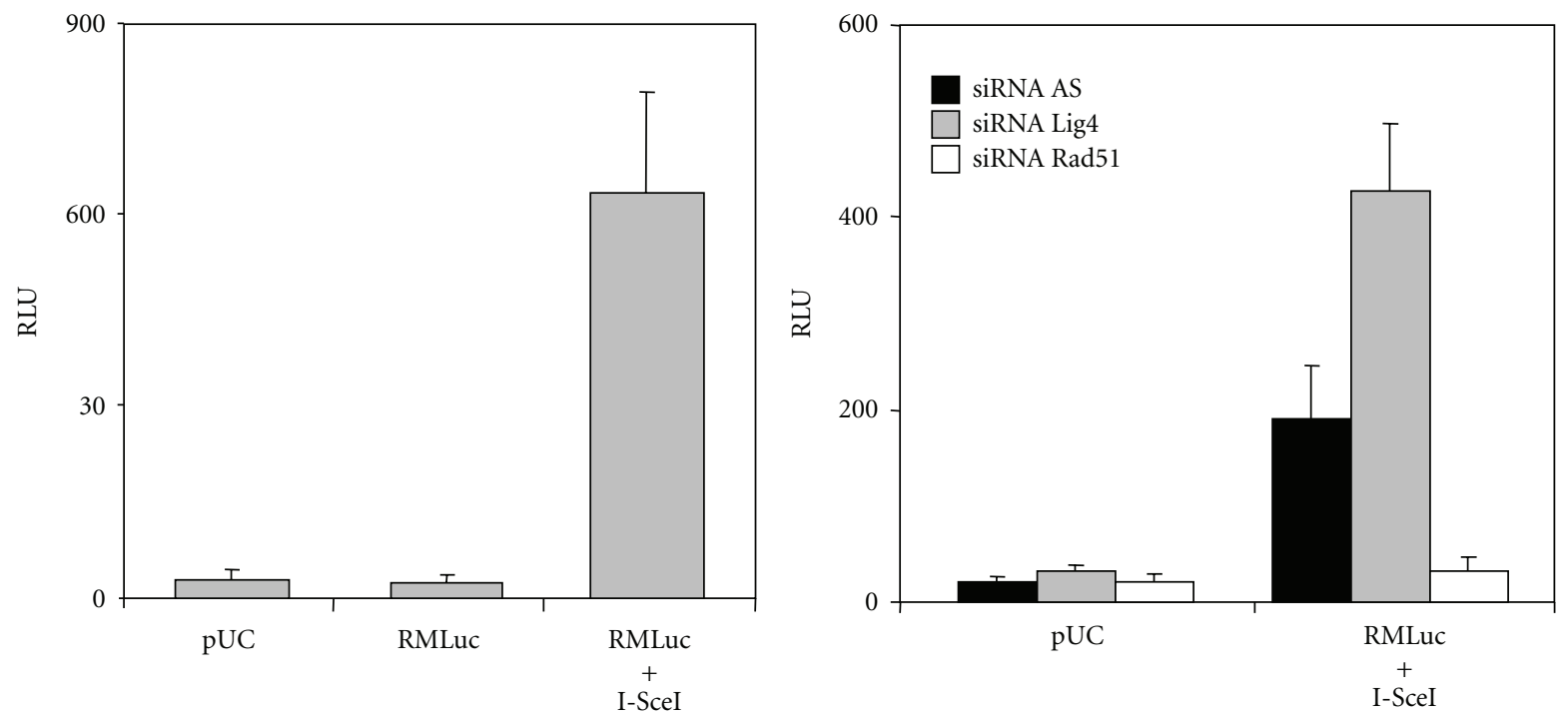

(b)

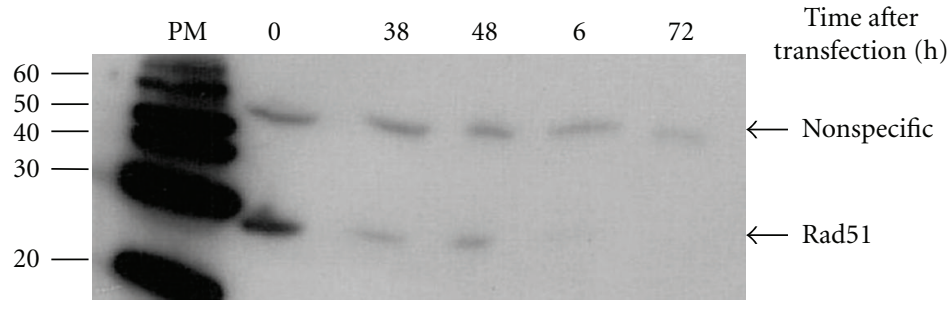

(c)

FIGURE 1: A cell-based assay for identifying factors stimulating I-SceI-induced HGT. (a) A reporter system for I-SceI-induced gene targeting. The firefly luciferase gene (Luc2) is inactive due to replacement of the first 22 base pairs (bp) by a 24 bp I-SceI site (vertical black box). The plasmids constructed for I-SceI-induced gene targeting are described as follows: RMLuc+I-SceI has (i) the first 22 bp of the luciferase gene surrounded by $1 \mathrm{~kb}$ of homologous sequence (hatched boxes); (ii) an I-SceI induction cassette under the control of a CMV promotor. The RMLuc plasmid does not contain the I-SceI expression cassette. (b) Validation of the cell-based assay. The E2 cell line carrying a single integrated copy of the reporter system described in (a) was transfected with empty vector (pUC), RMLuc, or RMLuc+I-SceI (left panel). Luciferase activity was analyzed 72 hours after transfection. The E2 cell line was also cotransfected with either pUC or with RMLuc+I-SceI plus siRNAs known to modulate gene targeting (right panel): RAD51 siRNA and LIG4 siRNA. The results obtained were compared with those for cotransfection with the control All Star (AS) siRNA. Luciferase activity was assessed 72 hours after transfection. (c) Western blot analysis of Rad51 protein levels at various times after transfection, for the E2 clone with RMLuc+I-SceI and RAD51 siRNA. Specific and nonspecific bands were detected at 30 and $50 \mathrm{kDa}$, respectively. 
using oligonucleotides F2: 5' -AGGATCTCCTGTCATCTCAC-3' and R12: 5'-CTTTCACAGTCCTGTACATCTTGT$3^{\prime}$. The percentage of knock-in events was calculated, taking into account the plating efficiency for transfected cells, which was estimated at 30\% (data not shown).

2.5. Targeted Integration at the hXPC4 Locus. On the day before transfection, $10^{6} 293 \mathrm{H}$ cells were used to seed $10 \mathrm{~cm}$ dishes. Cotransfection was performed with $3 \mu \mathrm{g}$ of meganuclease-encoding plasmid, $2 \mu \mathrm{g}$ of Knock-In matrix, and $1 \mathrm{nM}$ siRNA, using $25 \mu \mathrm{l}$ of Lipofectamine 2000 , according to the manufacturer's protocol. The Knock-In plasmid for the XPC $293 \mathrm{H}$ endogenous locus has left and right arms corresponding to isogenic sequences of $1.6 \mathrm{~kb}$ and $1.5 \mathrm{~kb}$ in size surrounding the hXPC4 meganuclease recognition site. These two homologous arms are separated by a $4.7 \mathrm{~kb}$ heterologous fragment of DNA containing a functional neomycin resistance gene under the control of a CMV promoter. The cells were trypsinized 72 hours after transfection, and 2000 cells per plate were used to seed $10 \mathrm{~cm}$ dishes. One week after seeding, we added $400 \mu \mathrm{g} / \mathrm{ml} \mathrm{G418}$ to the cells. One week later, G418-resistant clones were picked and amplified in 96-well plates. Genomic DNA was extracted with the ZR96 Quick-gDNA kit (Zymo Research), according to the manufacturer's protocol. The percentage of targeted events in stable transformants was analyzed by PCR screening with the oligonucleotides F3: 5'-CAAGCACCATAACAAACAACATTGA-3' and R1: 5'-ATCCGAAAATGGATATACAAGCTC-3' (cf. Figure 7).

2.6. Western Blot Analysis. All stages of protein extract preparation were carried out at $4^{\circ}$. Cells were washed with PBS, suspended in RIPA lysis buffer with $2 \mathrm{mM}$ PMSF, $1 \mathrm{mM}$ orthovanadate sodium, and protease inhibitor cocktail (Santa Cruz) and incubated for 30 minutes on ice. Extracts were centrifuged at $15,000 \mathrm{~g}$ for 30 minutes. The supernatant was retrieved, and its protein concentration was determined with the BCA protein assay. Boiled protein extract $(25 \mu \mathrm{g})$ was subjected to SDS-PAGE in a $10 \%$ polyacrylamide gel. After migration, the proteins were electrotransferred to nitrocellulose membrane and probed with specific antibodies: anti-Rad51 (Oncogene Research) and antirabbit HRP (Santa Cruz) antibodies. Antibody binding was detected with the Luminol detection kit (Santa Cruz).

2.7. RNA Analysis. We suspended $5 \times 10^{6}$ cells in $1 \mathrm{ml}$ of TRIzol (Invitrogen) and incubated them for five minutes. We then added $200 \mu \mathrm{l}$ of chloroform, and the extracts were centrifuged at $12000 \times \mathrm{g}$ for 20 minutes at $4^{\circ}$. The supernatant was retrieved. RNA was precipitated by adding one volume of $75 \%$ ethanol and purified with the PureLink RNA Micro kit (Invitrogen) according to the manufacturer's protocol. Reverse transcription was carried out on $500 \mathrm{ng}$ of RNA, with the SuperScript III system (Invitrogen). PCR was performed with $1 \mu \mathrm{l}$ of the RT products, with the following oligonucleotides: for EP300, Forward, $5^{\prime}$-CTTGTTCACAAACTCGTCCAAGCC- ${ }^{\prime}$ and Reverse $5^{\prime}$-TGTGATGGGAACTGAGTCTGAGG-3'; for

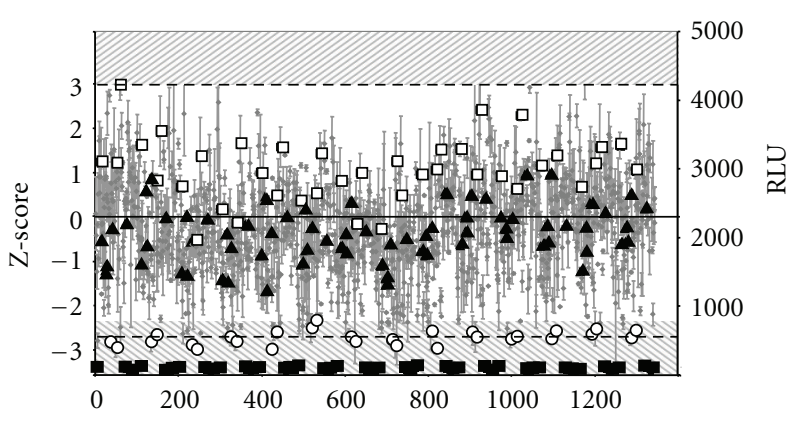

FIGURE 2: Representation of a typical primary screening run. Fourteen 96-well plates containing siRNAs for the screen and control siRNAs were transfected with RMLuc+I-SceI or pUC in duplicate. Seventy-two hours after transfection, luciferase activity was detected. Each dot represents the mean value per siRNA. The black box shows the luciferase value obtained following transfection with the empty vector (pUC), corresponding to background. Black triangles represent the values obtained for cotransfection with the AS siRNA and RMLuc+I-SceI; white circles represent the values obtained for cotransfection with RAD51 siRNA and RMLuc+ISceI. Finally, white squares represent the values obtained for cotransfection with LIG4 siRNA and RMLuc+I-SceI. The black line indicates the mean value for the run. Dashed boxes show the cutoff values for hit definition.

ATF7IP, Forward 5' -TGCCAAAAGAAGCCTTTCTGGTCC$3^{\prime}$ and Reverse $5^{\prime}$-TCAAATACAGCACACTGCAGCGC-3'; for GAPDH, Forward $5^{\prime}$-ATCATCTCTGCCCCCTCTGCTGATGCCCCC- $3^{\prime}$ and Reverse 5'-GATGACCTTGCCCACAGCCTTGGCAGCGCC-3' ; for I-SceI, Forward 5'-TAATGAACCTCGGTCCGAACTCTAAACTGC- $3^{\prime}$ and Reverse $5^{\prime}$-AATTTGTTACGCAGACCCTTAACCAGG-3' . PCR was stopped during the exponential phase of amplification, at 24 cycles, and the reaction mixture was loaded onto a $1 \%$ agarose gel. PCR products were quantified with ImageJ software.

\section{Results and Discussion}

3.1. Development of a High-Throughput Screening Assay. We developed a cell-based functional assay amenable to highthroughput screening for genome-wide screening for factors affecting nuclease-induced HGT. We constructed a reporter system based on an inactivated firefly luciferase gene, with HGT targeting this gene restoring readily detectable luciferase activity (Figure 1(a)). As luciferase inactivation resulted from the replacement of the first $22 \mathrm{bp}$ of the gene with an I-SceI target site, HGT could be induced by expression of the meganuclease. This reporter construct was stably introduced into the genome of the human GM00847 cell line, and a clone carrying a single-copy insertion was identified by Southern blot analysis (data not shown). Under our experimental conditions (see Section 2), we detected no activation of the luciferase gene in cells transfected with the repair matrix alone, indicating that classical HGT was not detectable in these conditions. By contrast, transfection 


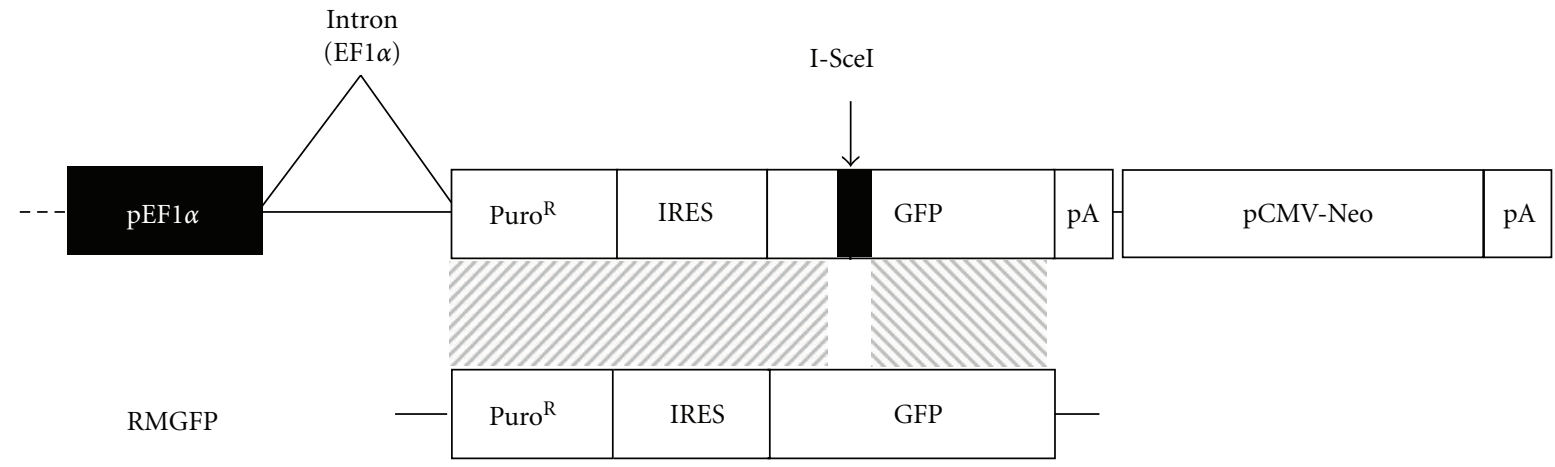

RMGFP + I-SceI

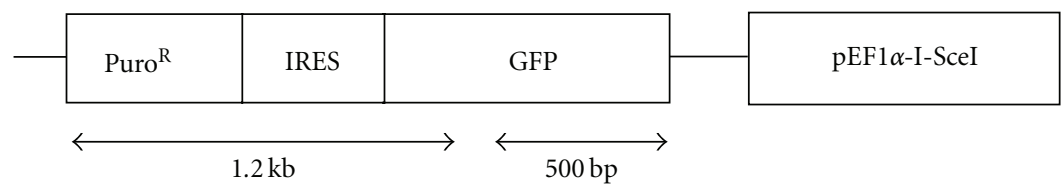

(a)

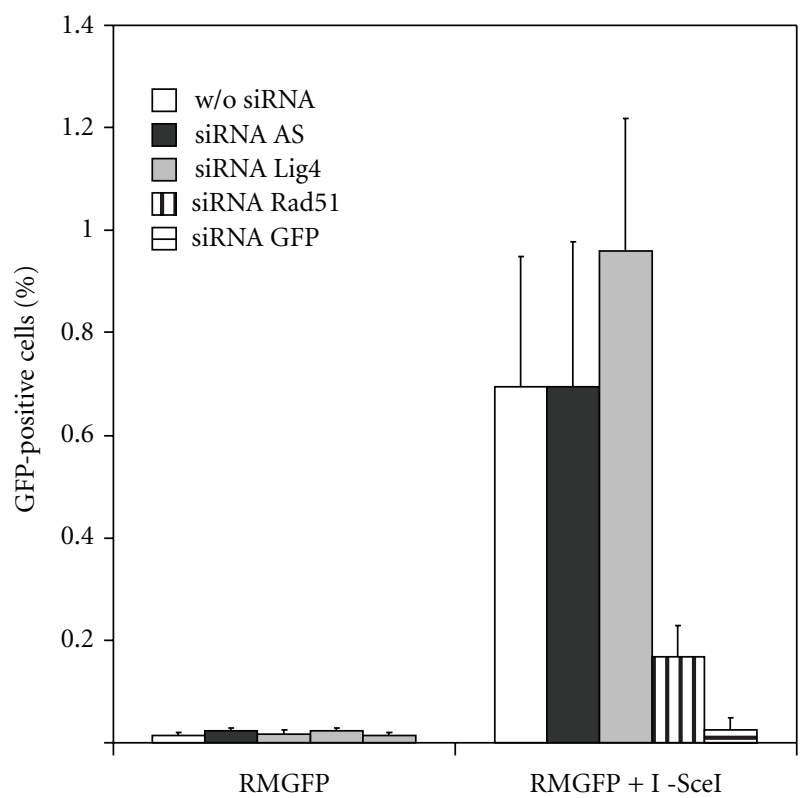

(b)

FIGURE 3: Cell-based assay for secondary screening. (a) Reporter system. The transgene used to assess I-SceI-induced gene targeting is integrated into the cGPS HEK-293 locus by expression of the I-CreI meganuclease. This transgene contains 1860 bp of the EF1 $\alpha$ human promoter sequence, followed by (i) a puromycin cassette (used for selection), (ii) an IRES sequence, (iii) a GFP gene inactivated by the insertion of an I-SceI site generating a stop codon, (iv) a neomycin resistance sequence (used for selection) under the control of a CMV promoter. Repair plasmid and I-SceI induction (RMGFP+I-SceI) and repair plasmid alone (RMGFP) used for the induction of gene targeting by I-SceI are shown in the following, with the length of homologous sequence indicated. GFP reporter gene expression is assessed by flow cytometry for the quantification of gene targeting efficiency. (b) A clone resistant to both puromycin and neomycin was cotransfected with RMGFP+I-SceI or RMGFP, with or without siRNA, or with the following siRNAs: AS, LIG4, RAD51, and GFP. GFP was detected by flow cytometry 96 hours after transfection. The results of four independent experiments are presented.

with a plasmid containing the repair matrix and an I-SceIexpressing cassette increased luciferase activity by a factor of 30 (Figure 1(b)).

For further validation of our assay, we cotransfected cells with the plasmid containing the repair matrix and the meganuclease-encoding cassette, together with an siRNA targeting the human RAD51 gene (Figure 1(b)). As a negative control, we used an siRNA with no known human targets (siRNA All STAR (AS) from QIAGEN). The RAD51 siRNA effectively knocked down the expression of its cognate target gene, as shown in Figure 1(c). As expected, it strongly inhibited (by a factor of six) I-SceI-induced HGT. The knockdown 


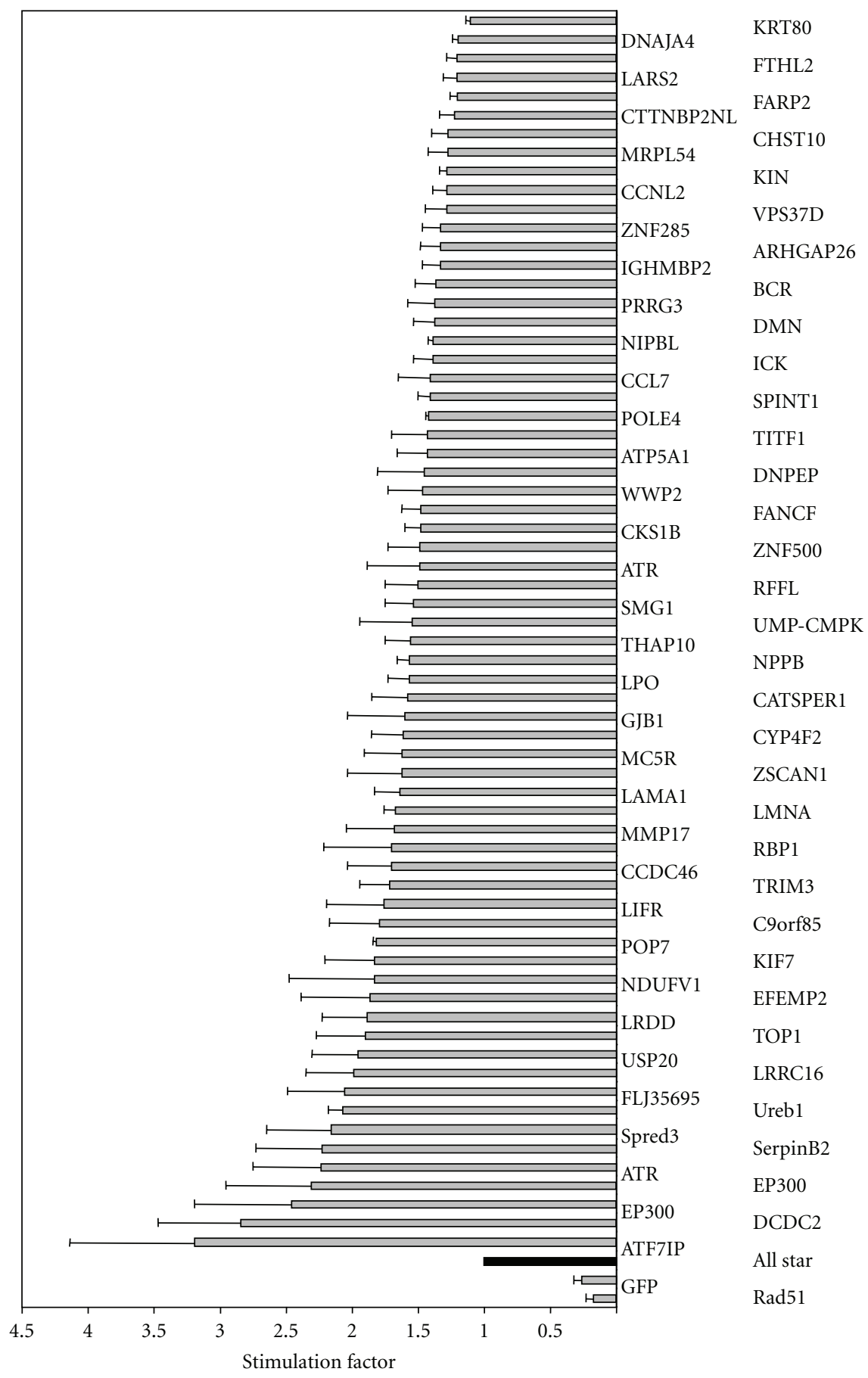

FIGURE 4: Hits selected after secondary screening. Cells were cotransfected with $200 \mathrm{ng}$ of RMGFP+I-SceI and a panel of different siRNAs, as indicated, at a final concentration of $33 \mathrm{nM}$. GFP fluorescence was detected by flow cytometry $96 \mathrm{~h}$ after transfection. The results are expressed as the stimulation factor, corresponding to the ratio of the percentage of GFP-positive cells in the presence of the siRNA hit to that following transfection with the control siRNA (AS). Four independent experiments were performed and Student's $t$-tests were used to assess the significance of differences in stimulation factor $(P$ value $<.05)$. Two siRNA controls were used to validate siRNA transfection: $R A D 51$ and GFP siRNAs. The RAD51 and GFP siRNAs decreased the percentage of GFP-positive cells by factors of 6 and 4 with respect to the AS control siRNA, demonstrating that the siRNAs were active. 


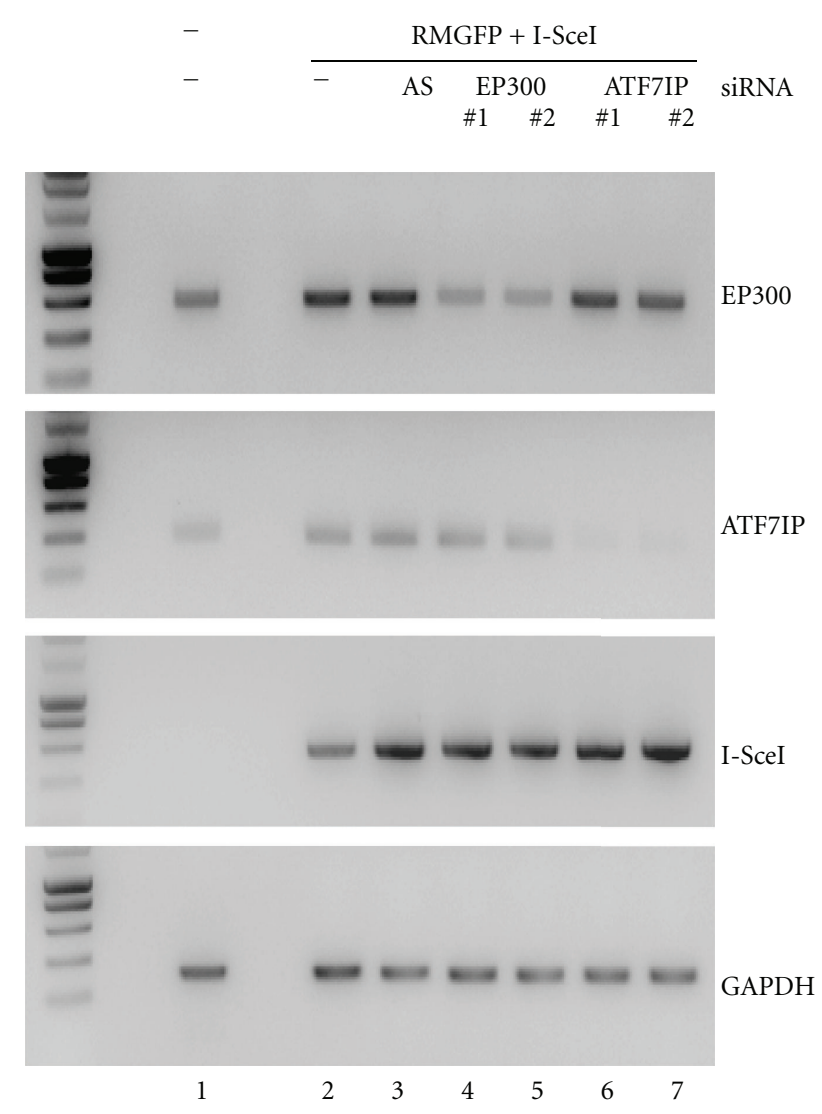

Figure 5: Characterization of EP300 and ATF7IP knockdown. Total RNA was extracted 48 hours after transfection with the indicated DNAs and siRNAs (two different siRNA sequences were used to target each of the ATF7IP and EP300 genes). RT-PCR was carried out to amplify mRNA transcribed from the ATF7IP, EP300, $G A P D H$, and I-SceI genes. The effects of siRNAs on their targets were monitored by analyzing band intensity after electrophoresis in $1 \%$ agarose gels. Lane 1, untransfected cells. In lanes 2 to 7 , the cells were transfected with the plasmid carrying the repair matrix and the I-SceI expression cassette. Lane 2, no siRNA; lane 3, AS siRNA; lanes 4 and 5, siRNA against EP300; lanes 6 and 7, siRNA against ATF7IP.

of NHEJ genes has been shown to stimulate DSB-induced recombination between chromosomal repeats $[47,51,54]$. By contrast, conflicting data have been obtained regarding the impact of NHEJ genes on classical HGT [48, 49]. We thus investigated the impact of an siRNA targeting the LIG4 gene. In our preliminary experiment, consistent with a recent RNAi study [54], the LIG4 siRNA was shown to increase HGT by a factor of two (Figure 1(b)). Altogether these results confirm the relevance of our experimental system for use in the search for factors affecting HGT.

3.2. Screening of a Genome-Wide Collection of siRNAs. We used our assay to screen a collection of siRNAs targeting 19,121 human genes (Qiagen). This collection included two individual siRNAs per gene, to overcome the problems of high false-positive and false-negative hit rates associated with siRNA pools and to improve confidence that the observed

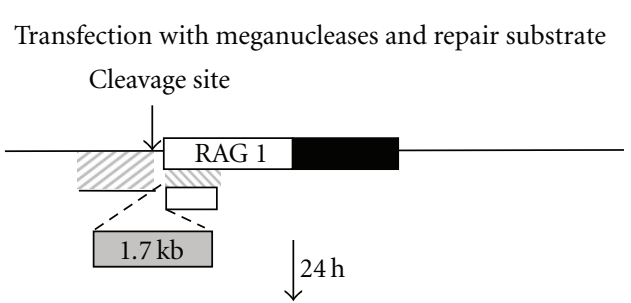

Cells dispensed into 96-well plates at density of 10 cells/well $\downarrow 2-3$ weeks (w/o selection)

Analysis of the locus for gene targeting events by specific PCR

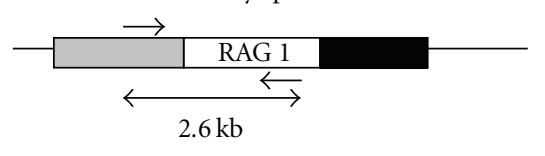

(a)

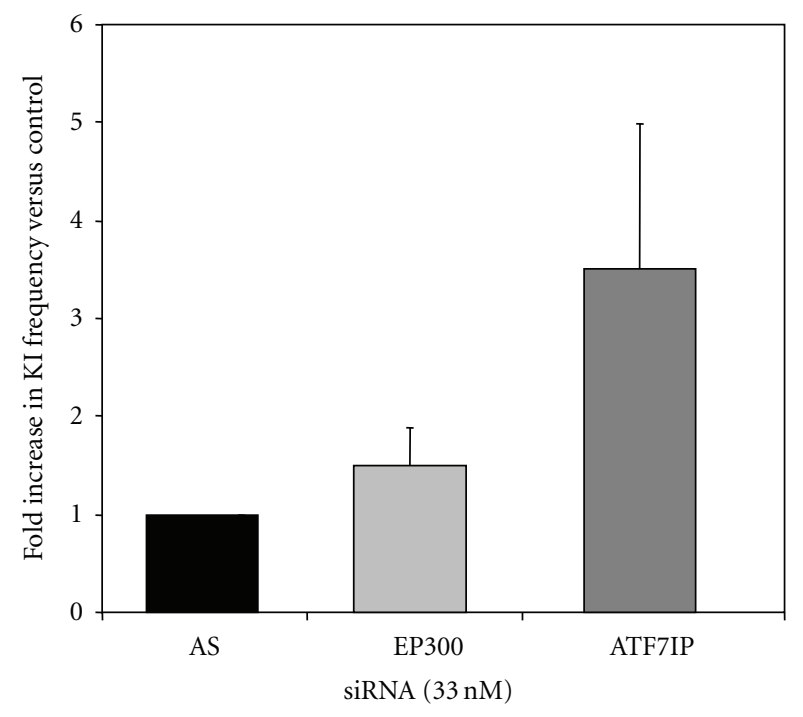

(b)

Figure 6: Impact of EP300 and ATF7IP knockdown on the frequency of targeted integration at the endogenous RAG1 locus. (a) Experimental design. (b) Results. Mean stimulation of targeted integration events. The stimulation factor is expressed with respect to control siRNA (AS). Data were obtained from 4 and 3 independent experiments with EP300 siRNA and ATF7IP siRNA, respectively.

hits were due to silencing of the intended genes. The quality of the runs was monitored by introducing siRNAs targeting the human RAD51 and LIG4 genes into each 96-well plate as positive controls. A typical experiment is shown in Figure 2. The luciferase signal increased from $65 \pm 15 \mathrm{RLU}$, in cells transfected with an empty vector (pUC), to $2000 \pm 400 \mathrm{RLU}$ following cotransfection with the plasmid containing the repair matrix and an I-SceI-expressing cassette and with the AS control siRNA. In this experiment, transient deficiencies of LIG4 and RAD51 genes resulted in luciferase signals of $3000 \pm 450$ and $550 \pm 100$ RLU, respectively. For all controls, the coefficient of variation $(\mathrm{CV}=\sigma / m$, where $\sigma$ is the standard deviation and $m$ the mean of the measured values) 
was found to be below $20 \%$ (19\%, 15\%, and $19 \%$ for AS, $L I G 4$, and RAD51, resp.) demonstrating the quality of the run. However, this level of variation is sufficient to have a significant effect on the scoring of an siRNA as positive or negative. Therefore, we decided to use a stringent cutoff point, to prevent the selection of too many false positives: siRNAs were considered as potential candidate stimulators of HGT if their $Z$-score was higher than 3 . The drawback of this strategy is the risk of a high rate of false negatives. Indeed under this condition, whereas transient LIG4 gene knockdown consistently led to the stimulation of HGT (1.4 \pm 0.3 ), it was scored as a positive hit in only 9 of the 35 runs required to screen the entire siRNA collection (data not shown). However, the RAD51 siRNA, which decreased HGT by a factor of six, resulted in weak signal, clearly different from the mean value of the run. These results illustrate the limits of our current screening system, which can easily miss factors having a modest effect on HGT. Moreover, the optimal timing between mRNA knockdown and the resulting phenotype may vary as a function of the gene targeted, cell type, siRNA sequence, metabolic pathway and meganuclease expression. The cotransfection strategy of siRNA and meganuclease-encoding vector could lead to a partial extinction of the targeted protein, whereas the meganuclease is at its optimum activity. However, it has been shown that treatment with siRNA targeting Ku70 and Xrcc4 reduced corresponding protein levels by $80-90 \% 48 \mathrm{~h}$ after transfection, with a return to normal levels by $96 \mathrm{~h}$ in HCT116 cell line (Bertolini, 2007 no. 7). Therefore, it is reasonable to think that cotransfection strategy is applicable, but it may underestimate the significance of the genes. Thus, although our primary screening assay was conducted with siRNAs targeting most of the relevant human genes, it should actually be considered far from exhaustive.

Nevertheless, we eventually identified 290 candidates, targeting 279 different genes, from 38,242 $(2 \times 19,121)$ siRNAs, and these candidates were then subjected to secondary screening (see the following). Several potential inhibitors of HGT were also identified, and a series of siRNAs targeting 348 different genes gave levels of inhibition at least similar to the RAD51 siRNA (signal lower than the mean signal with RAD51 siRNA plus half its standard deviation). However, despite their important potential applications in medical fields such as cancer treatment, siRNAs involved in the inhibition of HGT were not the focus of this study and were not processed by secondary screening.

3.3. Secondary Screening. High-throughput siRNA screening can lead to high false-positive rates. This problem was addressed in our experimental procedure by systematic duplication of the assay and the choice of a stringent cutoff point. However, we nevertheless designed an additional assay for secondary screening. We used the cGPS HEK-29 Full Kit (Cellectis, France) to create a cell line derived from HEK293 and carrying a single copy of the GFP coding sequence inactivated by the introduction of an I-SceI site (Figure 3(a)). Like the GM00847 derivative used in primary screening, this cell line can be used to monitor I-SceI-induced HGT. By contrast to the primary screening, this secondary screening method did not measure the global activity of a reporter gene (luciferase) in the cell population. Instead, we determined the number of cells that had acquired a functional GFP reporter gene using flow cytometry detection. Thus, siRNAs resulting in the mere enhancement of reporter gene expression should be counterselected at this step. Moreover, the two strains differ in terms of parental cell type, reporter gene, and integration locus. In this new cell line, HGT at the GFP locus was not detectable in the absence of I-SceI but was strongly stimulated when a meganuclease-encoding cassette was introduced with the repair matrix (Figure 3(b)). Consistent with our previous observations, transient RAD51 deficiencies inhibited gene targeting efficiency by factors of 4, while LIG4 siRNA had only a mild effect, stimulating HGT by a factor of 1.4 showing that this siRNA did not lead to a strong and robust stimulation of I-SceI-induced HGT frequency.

The 290 candidate siRNAs previously identified were tested in this new system. Sixty-six were confirmed as having a significant $(P<.05)$ stimulatory effect, increasing HGT by factors of 1.2 to 3 over the siRNA control (AS). These 66 candidates corresponded to 64 different candidate genes, with the ATR and EP300 genes each targeted by two different siRNAs (Figure 4). For eight genes (ATF7IP, DCDC2, EP300, ATR, SERPINB2, SPRED3, UREB1, and FLJ35695), HGT rates were more than doubled. None of the genes identified in our study was found in an esiRNA screening that was monitoring DSB-induced intrachromosomal homologous recombination [54]. Many factors may account for such discrepancies: cell type, the sequence and strength of the siRNA, and the nature of the events involved. Indeed, in our model, accessibility of the exogenous DNA repair template to the double-strand break site may be a major factor that was not addressed in this previous study since the repair template is present on the same chromatin. Therefore, our screening might identify gene involved not directly in HR mechanism but rather in regulation of HR such as the accessibility of the meganuclease and/or the exogenous DNA template to the cleavage site.

To confirm our data and rule out possible offtarget effects, new siRNAs (Invitrogen) targeting different sequences among the 21 best candidate genes were tested. As shown in Table 1, 12 of the new siRNAs significantly $(P<$ $.05)$ increased HGT, the strongest stimulation being achieved with the ATF7IP $(4.2 \pm 0.9)$ and EP300 $(4.2 \pm 1.7)$ siRNAs. We further characterized these two genes. Interestingly, they have been described as transcription factors and are involved in chromatin remodeling [56-59]. RT-PCR analysis showed that the expression of these genes was knocked down by both siRNAs (Figure 5). ATF7IP and EP300 mRNA levels were strongly decreased or undetectable in the presence of their cognate inhibitors, whereas no effect on GAPDH gene expression was observed. Importantly, these siRNAs had no effect on meganuclease expression, demonstrating that downregulation of the ATF7IP and EP300 genes had no impact on I-SceI expression.

Altogether, the stimulating activities on HGT, obtained for siRNAs with two cellular models and with sequences of 
TABLE 1: Validation of the candidate genes. Candidate genes were selected after secondary screening. siRNAs targeting various mRNA sequences were tested for their ability to stimulate homologous gene targeting. Results are the means of at least 3 independent experiments.

\begin{tabular}{|c|c|c|c|}
\hline siRNA target & Mean stimulation factor & Std & $P$ value \\
\hline ATF7IP & 3.6 & 1.0 & $<.05$ \\
\hline EP300 & 3.0 & 0.9 & $<.05$ \\
\hline SERPINB2 & 2.5 & 1.1 & $<.05$ \\
\hline NDUFV1 & 2.2 & 0.6 & $<.05$ \\
\hline$L R D D$ & 2.0 & 0.6 & $<.05$ \\
\hline ATR & 2.0 & 0.7 & $<.05$ \\
\hline POP7 & 1.8 & 0.6 & $<.05$ \\
\hline FLJ35695 & 1.8 & 0.2 & $<.05$ \\
\hline$D C D C 2$ & 1.6 & 0.6 & $<.05$ \\
\hline$R B P 1$ & 1.5 & 0.2 & $<.05$ \\
\hline LIFR & 1.5 & 0.6 & $<.05$ \\
\hline EFEMP2 & 1.4 & 0.2 & $<.05$ \\
\hline USP20 & 1.4 & 0.73 & $>.05$ \\
\hline TRIM3 & 1.4 & 0.67 & $>.05$ \\
\hline TOP1 & 1.3 & 0.5 & $>.05$ \\
\hline HUWE1 & 1.3 & 0.3 & $>.05$ \\
\hline SPRED3 & 1.3 & 0.6 & $>.05$ \\
\hline C9orf85 & 1.2 & 0.8 & $>.05$ \\
\hline$L R R C 16$ & 1.1 & 0.58 & $>.05$ \\
\hline CCDC46 & 1.0 & 0.3 & $>.05$ \\
\hline KIF7 & 0.9 & 0.4 & $>.05$ \\
\hline
\end{tabular}

different origins demonstrate the potential involvement of the corresponding genes on DSB-induced HGT regulation.

3.4. Knockdown of ATF7IP and EP300 Can Stimulate Meganuclease-Induced Gene Targeting in Endogenous Human Loci. For validation of the ability of the ATF7IP and EP300 siRNAs to increase HGT frequency at an endogenous locus in human cells, we used a meganuclease cleaving the human RAG1 locus described in a previous study [55]. The principle of the targeting experiment is described in Figure 6(a). Using triple transfection with the donor repair plasmid, the meganuclease-encoding vector, and siRNA, we determined the frequency of targeted homologous recombination events with a PCR screen, as previously described [55]. This PCR screen has been validated by the characterization, by Southern blotting, of positive clones from independent experiments, with no false positive identified among more than 50 clones (data not shown). Under the experimental conditions described here, gene targeting events at the RAG1 locus were detected in $0.7 \%$ of the transfected cells in the presence of the control siRNA (AS). By contrast, the introduction into the cells of the siRNA targeting the EP300 gene resulted in an increase by a factor of 1.5 , whereas siRNA directed against the ATF7IP gene increased the frequency of gene targeting events by a factor of 3.5 (Figure 6(b)).

Given the strong effect of the ATF7IP siRNA, we also assessed its impact on HGT at the human XPC locus. In this case, we used the XPC4 meganuclease, which is an optimized version of the XPC.c meganuclease described in a previous study [60]. As the frequency of DSB-induced recombination was lower at this locus (data not shown), we did not measure the absolute frequency of HGT. Instead, we measured the frequency of HGT among stable transformants: the rate of HGT versus RI of the repair matrix. This rate is used in many studies in which the absolute frequency of HGT is low, in plants [61] or mammalian stem cells [40, 62], for example. The experimental scheme is shown in Figure 7. We used a neomycin resistance $\left(\mathrm{Neo}^{\mathrm{R}}\right)$ cassette to select for transformants. G418-resistant clones were picked two weeks after transfection, amplified and characterized at the molecular level. Two independent experiments were conducted (Table 2). In the first, we obtained 5 targeted clones $(4.2 \%)$ from 120 transformants in the presence of the AS siRNA and 15 clones (10.3\%) from 146 transformants with the knockdown of ATF7IP expression. A second experiment performed in duplicate gave similar results, with 2 or 1 (2.4 or $1.3 \%)$ targeted clones from 83 or 73 transformants with AS, respectively, and 17 or 6 (14.9 or $10.3 \%)$ targeted clones from 114 or 58 transformants with the ATF7IP siRNA, respectively. These results indicate that siRNAs shown to increase I-SceI-induced gene targeting efficiency also increase the efficiency of homologous gene insertion induced by engineered I-CreI meganuclease at a natural locus.

Taken together, these data show that ATF7IP and EP300, two genes involved in transcription regulation and chromatin remodeling [56-59], can be considered as validated targets, at least for immortalized cells. Indeed, transient inactivation of these two genes may stimulate HGT at up to four different loci in human cells: the two endogenous loci, 
TABLE 2: Effect on gene targeting at the XPC4 locus of an siRNA targeting the ATF7IP gene.

\begin{tabular}{|c|c|c|c|c|c|}
\hline & siRNA & Number of $\mathrm{G} 418^{\mathrm{R}}$ clones & Number of $\mathrm{PCR}^{+}$clones & HGT (\%) & Fold stimulation \\
\hline \multirow{2}{*}{ Experiment 1} & AS & 120 & 5 & 4.2 & \\
\hline & ATF7IP & 146 & 15 & 10.3 & 2.4 \\
\hline \multirow{2}{*}{ Experiment 2} & AS & 83 & 2 & 2.4 & \\
\hline & ATF7IP & 114 & 17 & 14.9 & 6.2 \\
\hline \multirow{2}{*}{ Experiment 3} & AS & 73 & 1 & 1.3 & \\
\hline & ATF7IP & 58 & 6 & 10.3 & 7.9 \\
\hline
\end{tabular}

Transfection with meganucleases and repair substrate

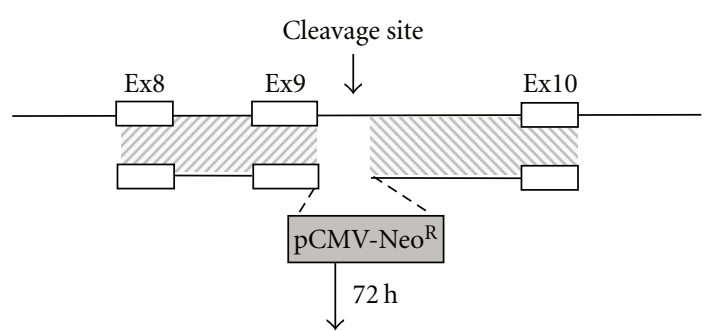

Cells dispensed at density of 2 cells/plate $(10 \mathrm{~cm})$

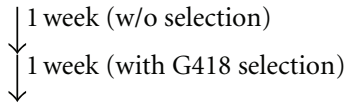

Picking of clones and amplification

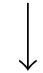

Analysis of gene targeting events by specific PCR

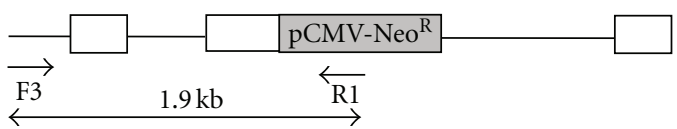

Figure 7: Targeted integration at the endogenous XPC4 locus: experimental design. The XPC4 target sequence is located in exon 9 of the XPC gene. Exons 8, 9, and 10 are shown in white boxes. Cleavage of the native XPC gene by the meganuclease yields a substrate for homologous recombination, which may use the repair plasmid depicted. Targeted integration events were detected by genomic PCR amplification carried out on neomycin-resistant clones.

hRAG1 and $h X P C 4$, and the two endogenous luciferase and GFP reporter loci (from the primary and secondary screen). Moreover, HGT was stimulated in three different cell types (GM00847, a HEK293 derivative, and 293H). Knockdown of $A T F 7 I P$, the strongest candidate, gave a 3.5 times increase in HGT at the human RAG1 locus and an up to 7 times increase at the XPC locus. EP300 is a histone acetylase that acetylates all four core histones in nucleosomes [63], thereby generating an epigenetic tag for transcriptional activation. ATF7IP is involved in histone methylation, another type of transcription-related epigenetic modification $[56,64]$ : it is required to stimulate the histone methyltransferase activity of SETDB1 [57]. SETDB1 was not among our primary hits, but it gave a 1.7 times increase in $Z$-score value in our primary screening (data not shown), indicating a stimulatory effect on the I-SceI-induced HGT luciferase signal. Altogether, these results suggest that chromatin remodelling may be an important mechanism regulating DSB-induced gene targeting. The exact mechanism of action of ATF7IP and EP300 knockdown in HGT regulation remains to be determined.

\section{Conclusion}

In this study we developed a two-step screening allowing the detection of factors modulating the efficiency of I-SceIinduced HGT. We screened an siRNA collection targeting 19,000 genes. This led us to the identification of 64 genes which down regulation stimulate DSB-induced HGT frequency. For twelve of the genes we could rule out an off-target effect since an siRNA targeting the same gene but with a different sequence could still stimulate HGT frequency. Surprisingly, the gene knockdowns having the strongest impact on the efficiency of DSB-induced HGT, ATF7IP, EP300, are not involved in DNA-DSB repair but rather are implicated in chromatin remodelling. These data suggest an important role of these mechanisms in regulating DSB-induced gene targeting. Further characterizations of these genes would be very valuable to determine if their downregulation could still stimulate gene targeting not induced by a DSB as well as any other HR mechanisms (such as intra- or interchromosomal HR) induced or not by a double-strand break.

In addition, several other candidates not involved in chromatin remodeling, such as ATR, LRDD, SERPINB2, $U R E B 1$, and TOP1, were selected after secondary screening. It will therefore be important to assess the effect of these siRNAs on meganuclease-induced HGT at other loci. Thus, it seems likely that several other enhancers of HGT could be identified by further experiments. In principle, factors stimulating HGT by different mechanisms should have synergistic effects, making it possible to achieve much higher levels of stimulation.

\section{Acknowledgment}

F. Delacôte C. Perez contributed equally to this work. 


\section{References}

[1] L. S. Symington, "Role of RAD52 epistasis group genes in homologous recombination and double-strand break repair," Microbiology and Molecular Biology Reviews, vol. 66, no. 4, pp. 630-670, 2002.

[2] R. H. Schiestl, J. Zhu, and T. D. Petes, "Effect of mutations in genes affecting homologous recombination on restriction enzyme-mediated and illegitimate recombination in Saccharomyces cerevisiae," Molecular and Cellular Biology, vol. 14, no. 7, pp. 4493-4500, 1994.

[3] O. Bezzubova, A. Silbergleit, Y. Yamaguchi-Iwai, S. Takeda, and J. M. Buerstedde, "Reduced X-ray resistance and homologous recombination frequencies in a $R A D 54^{-/-}$mutant of the chicken DT40 cell line," Cell, vol. 89, no. 2, pp. 185-193, 1997.

[4] Y. Yamaguchi-Iwai, E. Sonoda, J. M. Buerstedde et al., "Homologous recombination, but not DNA repair, is reduced in vertebrate cells deficient in RAD52," Molecular and Cellular Biology, vol. 18, no. 11, pp. 6430-6435, 1998.

[5] C. Morrison, A. Shinohara, E. Sonoda et al., "The essential functions of human Rad51 are independent of ATP hydrolysis," Molecular and Cellular Biology, vol. 19, no. 10, pp. 68916897, 1999.

[6] M. Takata, M. S. Sasaki, E. Sonoda et al., "The Rad51 paralog Rad51B promotes homologous recombinational repair," Molecular and Cellular Biology, vol. 20, no. 17, pp. 6476-6482, 2000.

[7] M. Takata, M. S. Sasaki, S. Tachiiri et al., "Chromosome instability and defective recombinational repair in knockout mutants of the five Rad51 paralogs," Molecular and Cellular Biology, vol. 21, no. 8, pp. 2858-2866, 2001.

[8] M. E. Moynahan, A. J. Pierce, and M. Jasin, "BRCA2 is required for homology-directed repair of chromosomal breaks," Molecular Cell, vol. 7, no. 2, pp. 263-272, 2001.

[9] M. E. Moynahan, J. W. Chiu, B. H. Koller, and M. Jasint, "Brcal controls homology-directed DNA repair," Molecular Cell, vol. 4, no. 4, pp. 511-518, 1999.

[10] J. Essers, R. W. Hendriks, S. M. A. Swagemakers et al., "Disruption of mouse RAD54 reduces ionizing radiation resistance and homologous recombination," Cell, vol. 89, no. 2, pp. 195-204, 1997.

[11] L. J. Niedernhofer, J. Essers, G. Weeda et al., "The structurespecific endonuclease Erccl-Xpf is required for targeted gene replacement in embryonic stem cells," EMBO Journal, vol. 20, no. 22, pp. 6540-6549, 2001.

[12] J. E. Haber, "Alternative endings," Proceedings of the National Academy of Sciences of the United States of America, vol. 105, no. 2, pp. 405-406, 2008.

[13] J. Guirouilh-Barbat, S. Huck, P. Bertrand et al., "Impact of the KU80 pathway on NHEJ-induced genome rearrangements in mammalian cells," Molecular Cell, vol. 14, no. 5, pp. 611-623, 2004.

[14] J. Guirouilh-Barbat, E. Rass, I. Plo, P. Bertrand, and B. S. Lopez, "Defects in XRCC4 and KU80 differentially affect the joining of distal nonhomologous ends," Proceedings of the National Academy of Sciences of the United States of America, vol. 104, no. 52, pp. 20902-20907, 2007.

[15] N. S. Verkaik, R. E. E. Esveldt-van Lange, D. Van Heemst et al., "Different types of $\mathrm{V}(\mathrm{D}) \mathrm{J}$ recombination and endjoining defects in DNA double-strand break repair mutant mammalian cells," European Journal of Immunology, vol. 32, no. 3, pp. 701-709, 2002.
[16] E. B. Kabotyanski, L. Gomelsky, J. O. Han, T. D. Stamato, and D. B. Roth, "Double-strand break repair in Ku86- and XRCC4-deficient cells," Nucleic Acids Research, vol. 26, no. 23, pp. 5333-5342, 1998.

[17] A. A. Hamilton and J. Thacker, "Gene recombination in X-raysensitive hamster cells," Molecular and Cellular Biology, vol. 7, no. 4, pp. 1409-1414, 1987.

[18] P. A. Jeggo and J. Smith-Ravin, "Decreased stable transfection frequencies of six X-ray-sensitive CHO strains, all members of the xrs complementation group," Mutation Research, vol. 218, no. 2, pp. 75-86, 1989.

[19] K. Sado, D. Ayusawa, A. Enomoto et al., "Identification of a Mutated DNA Ligase IV Gene in the X-ray-hypersensitive Mutant SX10 of Mouse FM3A Cells," Journal of Biological Chemistry, vol. 276, no. 13, pp. 9742-9748, 2001.

[20] J. Friesner and A. B. Britt, "Ku80- and DNA ligase IV-deficient plants are sensitive to ionizing radiation and defective in TDNA integration," Plant Journal, vol. 34, no. 4, pp. 427-440, 2003.

[21] F. Pâques and P. Duchateau, "Meganucleases and DNA double-strand break-induced recombination: perspectives for gene therapy," Current Gene Therapy, vol. 7, no. 1, pp. 49-66, 2007.

[22] J. A. Aten, J. Stap, P. M. Krawczyk et al., "Dynamics of DNA double-strand breaks revealed by clustering of damaged chromosome domains," Science, vol. 303, no. 5654, pp. 92-95, 2004.

[23] S. L. Gasior, H. Olivares, UY. Ear, D. M. Hari, R. Weichselbaum, and D. K. Bishop, "Assembly of RecA-like recombinases: distinct roles for mediator proteins in mitosis and meiosis," Proceedings of the National Academy of Sciences of the United States of America, vol. 98, no. 15, pp. 8411-8418, 2001.

[24] J. M. Hinz, N. A. Yamada, E. P. Salazar, R. S. Tebbs, and L. H. Thompson, "Influence of double-strand-break repair pathways on radiosensitivity throughout the cell cycle in $\mathrm{CHO}$ cells," DNA Repair, vol. 4, no. 7, pp. 782-792, 2005.

[25] J. S. Kim, T. B. Krasieva, H. Kurumizaka, D. J. Chen, A. M. R. Taylor, and K. Yokomori, "Independent and sequential recruitment of NHEJ and HR factors to DNA damage sites in mammalian cells," Journal of Cell Biology, vol. 170, no. 3, pp. 341-347, 2005.

[26] K. Rothkamm, I. Krüger, L. H. Thompson, and M. Löbrich, "Pathways of DNA double-strand break repair during the mammalian cell cycle," Molecular and Cellular Biology, vol. 23, no. 16, pp. 5706-5715, 2003.

[27] Y. Saintigny, F. Delacôte, D. Boucher, D. Averbeck, and B. S. Lopez, "XRCC4 in G1 suppresses homologous recombination in S/G2, in G1 checkpoint-defective cells," Oncogene, vol. 26, no. 19, pp. 2769-2780, 2007.

[28] M. Takata, M. S. Sasaki, E. Sonoda et al., "Homologous recombination and non-homologous end-joining pathways of DNA double-strand break repair have overlapping roles in the maintenance of chromosomal integrity in vertebrate cells," EMBO Journal, vol. 17, no. 18, pp. 5497-5508, 1998.

[29] F. Delacôte and B. S. Lopez, "Importance of the cell cycle phase for the choice of the appropriate DSB repair pathway, for genome stability maintenance: the trans-S double-strand break repair model," Cell Cycle, vol. 7, no. 1, pp. 33-38, 2008.

[30] K. D. Hanson and J. M. Sedivy, "Analysis of biological selections for high-efficiency gene targeting," Molecular and Cellular Biology, vol. 15, no. 1, pp. 45-51, 1995. 
[31] S. L. Mansour, K. R. Thomas, and M. R. Capecchi, "Disruption of the proto-oncogene int-2 in mouse embryo-derived stem cells: a general strategy for targeting mutations to nonselectable genes," Nature, vol. 336, no. 6197, pp. 348-352, 1988.

[32] B. S. Chevalier and B. L. Stoddard, "Homing endonucleases: structural and functional insight into the catalysts of intron/intein mobility," Nucleic Acids Research, vol. 29, no. 18, pp. 3757-3774, 2001.

[33] B. L. Stoddard, "Homing endonuclease structure and function," Quarterly Reviews of Biophysics, vol. 38, no. 1, pp. 49-95, 2005.

[34] J. Smith, M. Bibikova, F. G. Whitby, A. R. Reddy, S. Chandrasegaran, and D. Carroll, "Requirements for double-strand cleavage by chimeric restriction enzymes with zinc finger DNA-recognition domains," Nucleic Acids Research, vol. 28, no. 17, pp. 3361-3369, 2000.

[35] M. H. Porteus and D. Carroll, "Gene targeting using zinc finger nucleases," Nature Biotechnology, vol. 23, no. 8, pp. 967-973, 2005.

[36] Y. G. Kim, J. Cha, and S. Chandrasegaran, "Hybrid restriction enzymes: zinc finger fusions to Fok I cleavage domain," Proceedings of the National Academy of Sciences of the United States of America, vol. 93, no. 3, pp. 1156-1160, 1996.

[37] A. Lombardo, P. Genovese, C. M. Beausejour et al., "Gene editing in human stem cells using zinc finger nucleases and integrase-defective lentiviral vector delivery," Nature Biotechnology, vol. 25, no. 11, pp. 1298-1306, 2007.

[38] M. L. Maeder, S. Thibodeau-Beganny, A. Osiak et al., "Rapid "open-source" engineering of customized zinc-finger nucleases for highly efficient gene modification," Molecular Cell, vol. 31, no. 2, pp. 294-301, 2008.

[39] F. D. Urnov, J. C. Miller, YA. L. Lee et al., "Highly efficient endogenous human gene correction using designed zincfinger nucleases," Nature, vol. 435, no. 7042, pp. 646-651, 2005.

[40] J. Zou, M. L. Maeder, P. Mali et al., "Gene targeting of a disease-related gene in human induced pluripotent stem and embryonic stem cells," Cell Stem Cell, vol. 5, no. 1, pp. 97-110, 2009.

[41] R. C. DeKelver, V. M. Choi, E. A. Moehle et al., "Functional genomics, proteomics, and regulatory DNA analysis in isogenic settings using zinc finger nuclease-driven transgenesis into a safe harbor locus in the human genome," Genome Research, vol. 20, no. 8, pp. 1133-1142, 2010.

[42] R. J. Yáñez and A. C. G. Porter, "Differential effects of Rad52p overexpression on gene targeting and extrachromosomal homologous recombination in a human cell line," Nucleic Acids Research, vol. 30, no. 3, pp. 740-748, 2002.

[43] R. J. Yáñez and A. C. G. Porter, "Gene targeting is enhanced in human cells overexpressing hRAD51," Gene Therapy, vol. 6, no. 7, pp. 1282-1290, 1999.

[44] O. G. Shcherbakova, V. A. Lanzov, H. Ogawa, and M. V. Filatov, "Overexpression of bacterial RecA protein stimulates homologous recombination in somatic mammalian cells," Mutation Research, vol. 459, no. 1, pp. 65-71, 2000.

[45] H. Shaked, C. Melamed-Bessudo, and A. A. Levy, "Highfrequency gene targeting in Arabidopsis plants expressing the yeast RAD54 gene," Proceedings of the National Academy of Sciences of the United States of America, vol. 102, no. 34, pp. 12265-12269, 2005.

[46] C. Di Primio, A. Galli, T. Cervelli, M. Zoppè, and G. Rainaldi, "Potentiation of gene targeting in human cells by expression of Saccharomyces cerevisiae Rad52," Nucleic Acids Research, vol. 33, no. 14, pp. 4639-4648, 2005.

[47] A. J. Pierce, P. Hu, M. Han, N. Ellis, and M. Jasin, "Ku DNA end-binding protein modulates homologous repair of doublestrand breaks in mammalian cells," Genes and Development, vol. 15, no. 24, pp. 3237-3242, 2001.

[48] J. Domínguez-Bendala, M. Masutani, and J. McWhir, "Downregulation of PARP-1, but not of Ku80 or DNA-PK, results in higher gene targeting efficiency," Cell Biology International, vol. 30, no. 4, pp. 389-393, 2006.

[49] L. R. Bertolini, M. Bertolini, E. A. Maga, K. R. Madden, and J. D. Murray, "Increased gene targeting in Ku70 and Xrcc4 transiently deficient human somatic cells," Molecular Biotechnology, vol. 41, no. 2, pp. 106-114, 2009.

[50] S. Lambert and B. S. Lopez, "Characterization of mammalian RAD51 double strand break repair using non-lethal dominant-negative forms," EMBO Journal, vol. 19, no. 12, pp. 3090-3099, 2000.

[51] F. Delacôte, M. Han, T. D. Stamato, M. Jasin, and B. S. Lopez, "An xrcc4 defect or Wortmannin stimulates homologous recombination specifically induced by double-strand breaks in mammalian cells," Nucleic Acids Research, vol. 30, no. 15, pp. 3454-3463, 2002.

[52] S. R. Bartz, Z. Zhang, J. Burchard et al., "Small interfering RNA screens reveal enhanced cisplatin cytotoxicity in tumor cells having both BRCA network and TP53 disruptions," Molecular and Cellular Biology, vol. 26, no. 24, pp. 9377-9386, 2006.

[53] C. J. Lord, S. McDonald, S. Swift, N. C. Turner, and A. Ashworth, "A high-throughput RNA interference screen for DNA repair determinants of PARP inhibitor sensitivity," DNA Repair, vol. 7, no. 12, pp. 2010-2019, 2008.

[54] M. Słabicki, M. Theis, D. B. Krastev et al., "A genome-scale DNA repair RNAi screen identifies SPG48 as a novel gene associated with hereditary spastic paraplegia," PLoS Biology, vol. 8, no. 6, Article ID e1000408, 2010.

[55] S. Grizot, J. Smith, F. Daboussi et al., "Efficient targeting of a SCID gene by an engineered single-chain homing endonuclease," Nucleic Acids Research, vol. 37, no. 16, Article ID gkp548, pp. 5405-5419, 2009.

[56] N. Fujita, S. Watanabe, T. Ichimura et al., "MCAF mediates MBD1-dependent transcriptional repression," Molecular and Cellular Biology, vol. 23, no. 8, pp. 2834-2843, 2003.

[57] H. Wang, W. An, R. Cao et al., "mAM facilitates conversion by ESET of dimethyl to trimethyl lysine 9 of histone $\mathrm{H} 3$ to cause transcriptional repression," Molecular Cell, vol. 12, no. 2, pp. 475-487, 2003.

[58] T. Ichimura, S. Watanabe, Y. Sakamoto, T. Aoto, N. Pujita, and M. Nakao, "Transcriptional repression and heterochromatin formation by MBD1 and MCAF/AM family proteins," Journal of Biological Chemistry, vol. 280, no. 14, pp. 13928-13935, 2005.

[59] A. K. Ghosh and J. Varga, "The transcriptional coactivator and acetyltransferase p300 in fibroblast biology and fibrosis," Journal of Cellular Physiology, vol. 213, no. 3, pp. 663-671, 2007.

[60] S. Arnould, C. Perez, J. P. Cabaniols et al., "Engineered I-CreI derivatives cleaving sequences from the human XPC gene can induce highly efficient gene correction in mammalian cells," Journal of Molecular Biology, vol. 371, no. 1, pp. 49-65, 2007.

[61] R. Terada, H. Urawa, Y. Inagaki, K. Tsugane, and S. Iida, "Efficient gene targeting by homologous recombination in rice," Nature Biotechnology, vol. 20, no. 10, pp. 1030-1034, 2002. 
[62] D. Hockemeyer, F. Soldner, C. Beard et al., "Efficient targeting of expressed and silent genes in human ESCs and iPSCs using zinc-finger nucleases," Nature Biotechnology, vol. 27, no. 9, pp. 851-857, 2009.

[63] V. V. Ogryzko, R. L. Schiltz, V. Russanova, B. H. Howard, and Y. Nakatani, "The transcriptional coactivators p300 and CBP are histone acetyltransferases," Cell, vol. 87, no. 5, pp. 953-959, 1996.

[64] Z. Arany, W. R. Sellers, D. M. Livingston, and R. Eckner, "E1A-associated p300 and CREB-associated CBP belong to a conserved family of coactivators," Cell, vol. 77, no. 6, pp. 799800, 1994. 

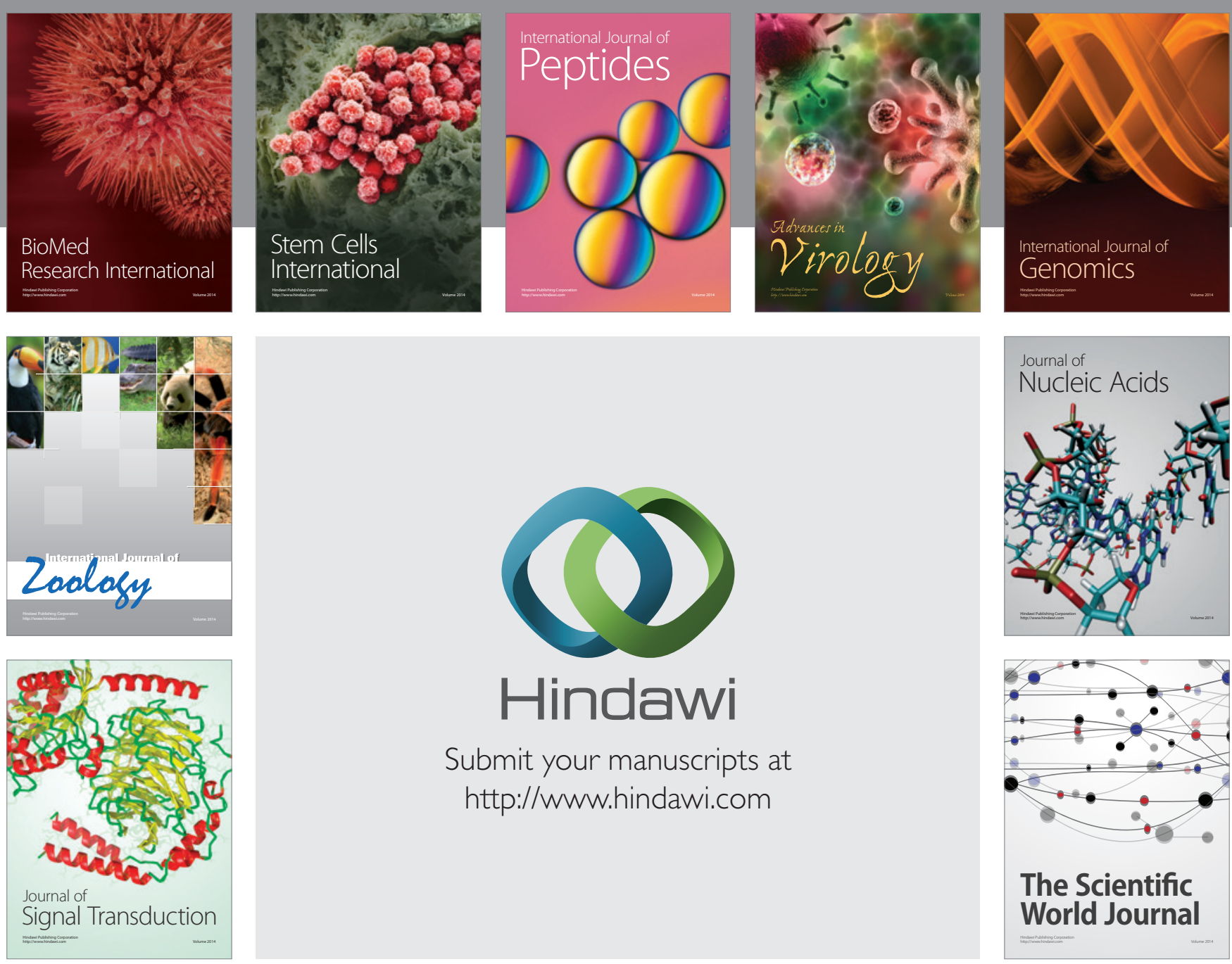

Submit your manuscripts at

http://www.hindawi.com
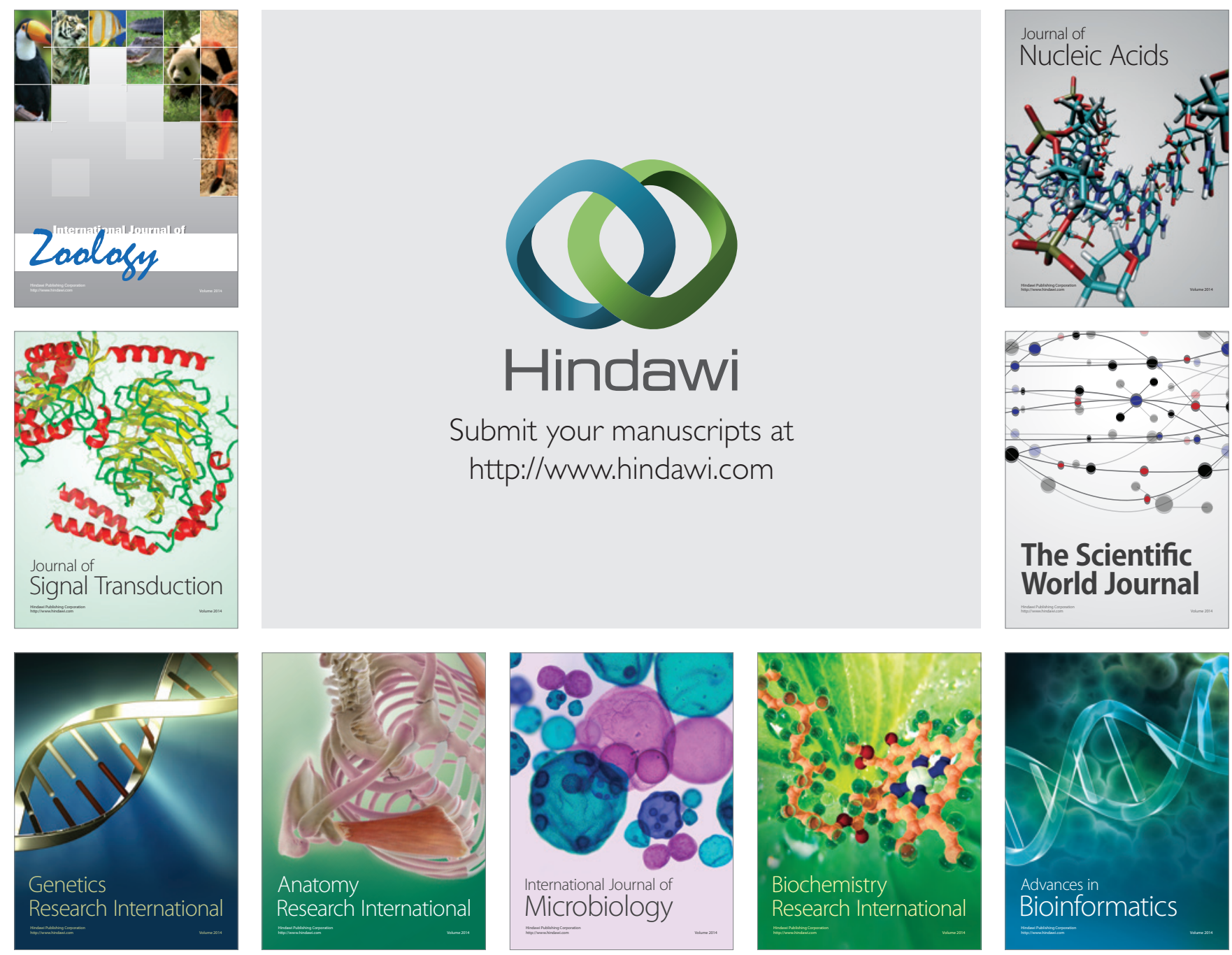

The Scientific World Journal
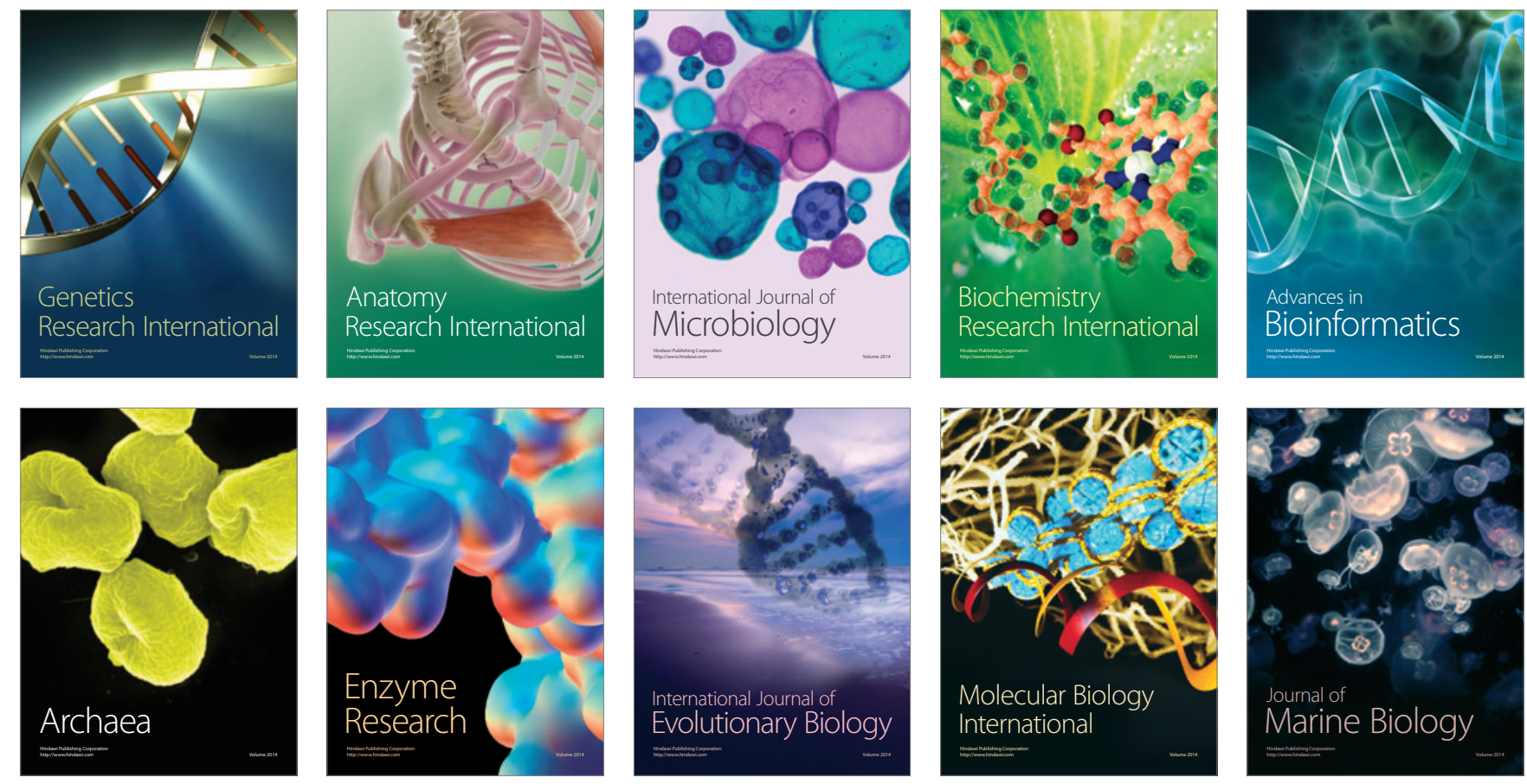